\title{
Transscaphoid perilunate dislocation
}

\author{
Brian T. Kloss • Shaheena R. Patierno • \\ Anne Marie Sullivan
}

Received: 19 April 2010 / Accepted: 21 June 2010/Published online: 4 September 2010

(C) Springer-Verlag London Ltd 2010

A 24-year-old male presented to the ED after a fall of approximately 25 feet from a rooftop. As he landed, he attempted to break his fall with an outstretched hand. His injuries were limited to right-sided acetabular and pubic rami fractures, and the wrist fracture-dislocation shown here (Figs. 1, 2, 3, 4).

Perilunate dislocations are often accompanied by scaphoid fractures due to the stresses from the high-energy impact to the wrist. Most patients present after a fall from a height onto an outstretched hand, with the wrist in a hyperextended and ulnar-deviated position [1]. Mayfield et al. described the mechanism of perilunate dislocations as a four-stage process. In the first stage, the radioscaphocapitate ligament and the scapholunate interosseous ligament rupture. Then dislocation of the capitolunate joint occurs as the injury advances through the space of Poirier. The

All work was completed at SUNY Upstate Medical University.

IRB exemption for a case report was obtained.

Brian T. Kloss, DO, JD, PA-C has ultimate control of the submitted abstract and case report/clinical image.

\footnotetext{
B. T. Kloss $(\bowtie) \cdot$ S. R. Patierno $\cdot$ A. M. Sullivan

Department of Emergency Medicine,

SUNY Upstate Medical University,

550 East Genesee Street,

Syracuse, NY 13202, USA

e-mail: klossb@upstate.edu

S. R. Patierno

e-mail: Bielmans@upstate.edu

A. M. Sullivan

e-mail: Adena@upstate.edu
}

lunotriquetral interosseous ligament breaks before finally the lunate becomes dislocated [2]. The incidence of perilunate dislocations is unknown as they often go undiagnosed.

Anteroposterior (AP) and lateral wrist radiographs are required for the diagnosis. In a perilunate dislocation, the lunate remains aligned with the distal radius; however, the capitate is dislocated dorsally. It is best seen on a lateral

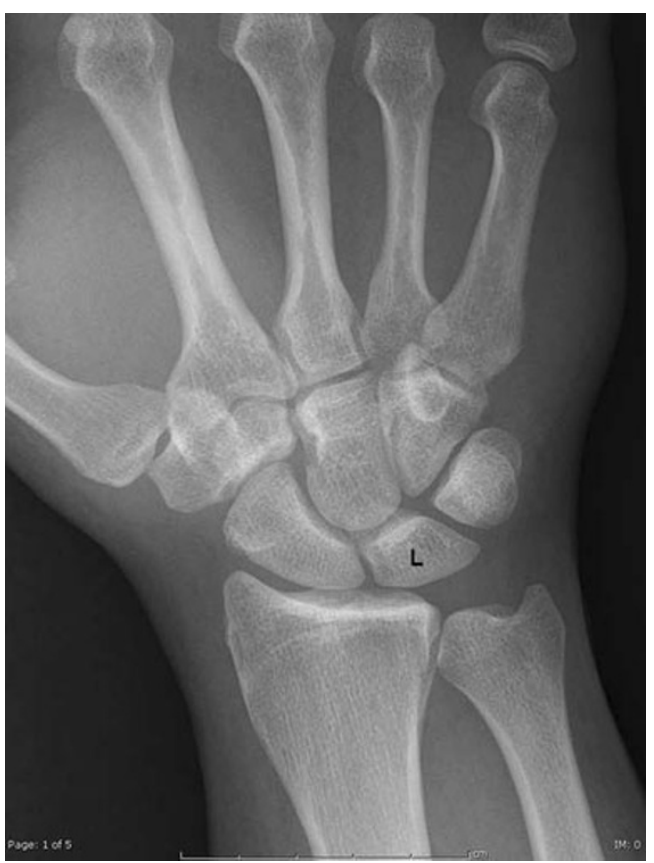

Fig. 1 On a normal AP wrist the lunate (L) has a nice rhomboid shape 


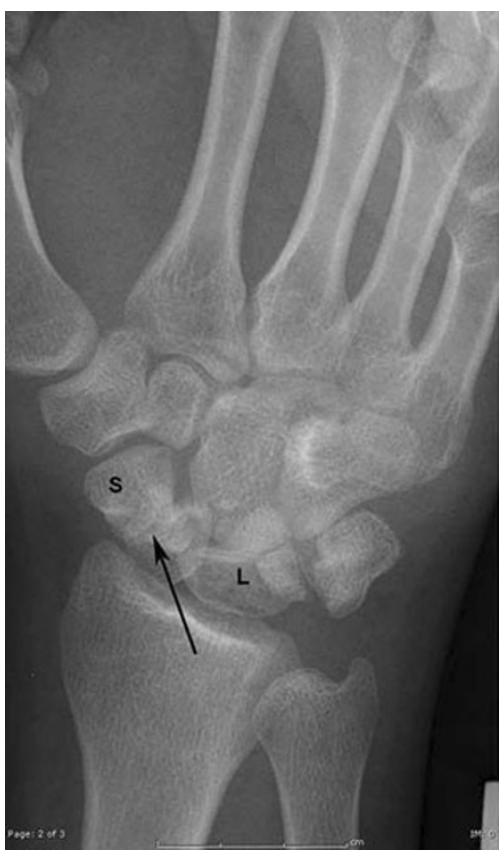

Fig. 2 Here the lunate (L) is pie-shaped and dislocated. The schaphoid (S) is fractured as indicated by the arrow

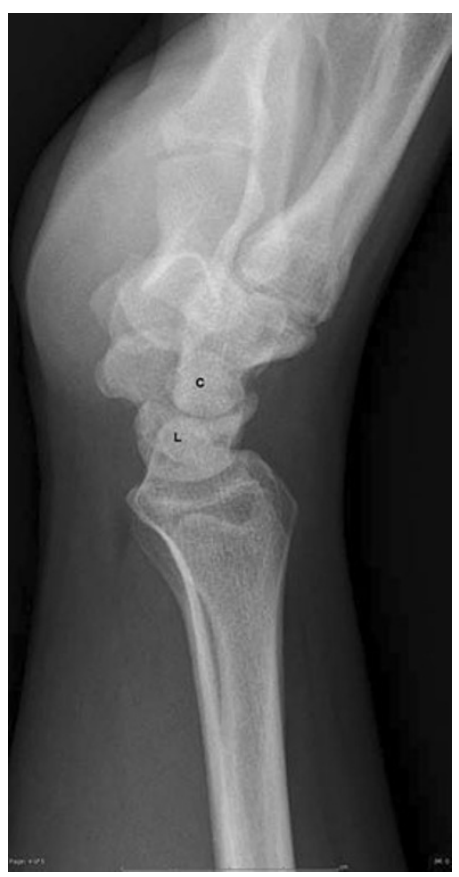

Fig. 3 On a normal lateral wrist, the capitate (C) sits within the convexity of the lunate (L)

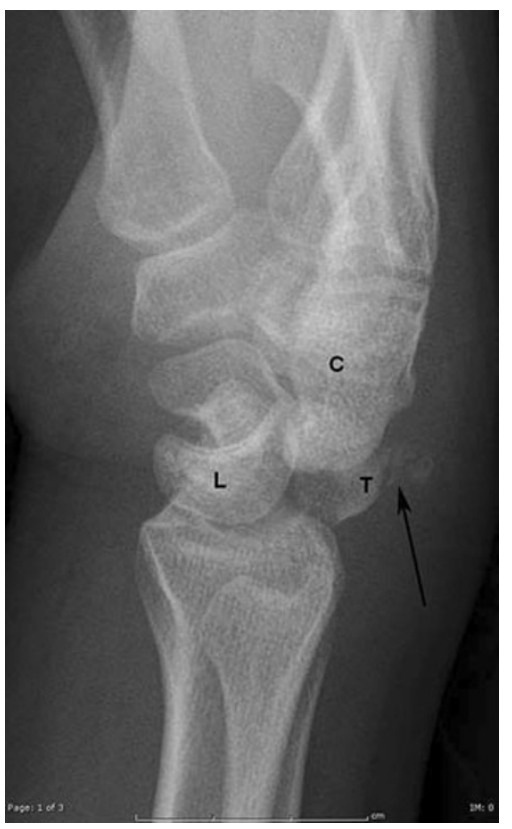

Fig. 4 Here the lunate (L) remains in the normal position while the capitate $(\mathrm{C})$ is dislocated posteriorly. In our patient, the triquetral bone is also fractured, as indicated by the arrow

view of the wrist [3]. Our patient also sustained a triquetral fracture, indicated by the arrow on the lateral view. The arrow on the AP view shows the commonly associated scaphoid fracture. In addition to visible deformity of the wrist, there can be decreased two-point sensation present in the median nerve distribution [4].

Management consists of reduction and immobilizing the wrist in a volar splint. Our patient was reduced at the bedside, stabilized and underwent successful ORIF the following day.

\section{References}

1. Dobyns J, Linscheid R (1985) Traumatic instability of the wrist. Am Acad Orthop Surg 34:182-199

2. Mayfield J, Johnson R, Kilcoyne R (1980) Carpal dislocations: pathomechanics and progressive perilunar instability. J Hand Surg Am 5:226-241

3. Harwood-Nuss A (2001) The clinical practice of emergency medicine, 3rd edn. Lippincott Williams \& Wilkins, Philadelphia

4. Marx JR (2002) Emergency medicine concepts and clinical practice, 5th edn. Mosby, St Louis 